final alkaline liquid some sodium amalgam, gently heating, and finally adding a drop or so of very dilute solution of potassium permanganate. In the presence of either iod-eosin or bromeosin green fluorescence is developed. This test, however, presents no advantage in the case of brom-eosin.

\title{
THE ELECTROLYTIC SEPARATION OF THE METALS OF THE SECOND GROUP.
}

\author{
By SAMUEL C. SCHMUCKER.
}

Received July 8, 1893 .

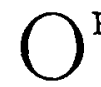

$F$ recent years the determination of metals quantitatively by the methods of electro-chemical analysis has grown into great popularity. The exceedingly accurate results, the simple forms obtained, and the ease with which it is possible to determine the absolute purity of the deposits all combine to make electrolytic methods highly desirable. Hitherto most of the operations have served simply to determine quantitatively the amount of one ingredient present, while comparatively less success has attended the separations of metals from each other. It is true that many valuable separations are known, the results of which have been published in the various chemical journals and in the few books devoted to the subject. But the list of separations of metals in the same group, and of separations of the different groups, is far from complete; and it is to this point that those chemists interested in electrolytic work are now giving their most earnest attention. Here the field seems at present likely best to repay the investigator.

As an example of a gap desirable to fill, I would cite the case of those metals known to analytical chemists as the metals of the second group, viz.: arsenic, antimony, tin, mercury (ic), lead, bismuth, copper, and cadmium. We have no electrolytic method serving for the separation of the first three from any of the later members. An examination of the literature of the subject would disclose to the student of electrolysis that should he encounter, for instance, a mixture containing copper, arsenic, antinony, and tin, he would find himself advised to abandon 
the current and employ the usual gravimetric method of digesting with sodium sulphide to effect the separation of copper from the other constituents. Nor is this by any means a solitary example. It is true, individual separations have been made in this group. For example, Smith and Frankel' succeeded in separating copper from arsenic, both in cyanide solution and in ammoniacal solution in which the arsenic was in the form of pentoxide and there was much free ammonia. The results in this latter instance have been confirmed by McKay. Very recently, Smith and Wallace ( $J$. Anal. Appl. Chcm. 7, 4) have printed an account of their successful separation, in very varying proportions, of copper from antimony, in alkaline tartrate solutions. These are the first successful results where antimony was present as more than a bare trace. Copper has never been separated from tin. Cadmium has no recorded separation from either antimony or tin; it has, however, been separated by Snith and Frankel from arsenic in cyanide solution. The case is in no wise better with either lead or bismuth. Solutions of either of these with any of the other three ( $\mathrm{As}, \mathrm{Sb}, \mathrm{Sn}$ ) have defied separation. Concerning mercury (ic) there is a little more to be said. If a mercuric solution contains also arsenic in the pentoxide form, and a decided excess of potassium cyanide, the mercury can be separated without difficulty. These results have suggested the question whether it is possible to find a general method suitable for the separation of any of the basic oxides of this second group from any or all of the acid oxides of the same group. This problen I have endeavored to solve. The method employed by Smith and Wallace for the separation of copper from antimony, suggested that in the alkaline tartrates might lie the key to the situation; and the separations from arsenic suggested, also, that it would be well to have the acid oxides in their highest state of oxidization. The results have fully justified my utmost expectation, and so far as they have been prosecuted, have been uniformly accurate. Inasmuch as we already have a separation of copper from arsenic, and of copper from antimony, my first attention was turned to the separation of

1Am. Ch'm. J., I2, 428. 
COPPER FROM TIN.

A solution of copper sulphate was made containing 0.0999 grams of metallic copper in each portion measuring ten cc. About one-tenth of a gram (varying from $0.1020-0.1057 \mathrm{gram}$ ) of metallic tin was dissolved in hydrochloric acid, and bromine water added until the solution remained colored with the bromine to insure complete oxidation. I was led to suspect the presence of iron in the tin, and as this metal is deposited by the current from an alkaline tartrate solution, it became necessary to secure its removal. The tin solution was accordingly evaporated to dryness, taken up with caustic soda, the solution diluted, the iron filtered off, and the filtrate containing the tin (as sodium stannate) was neutralized with tartaric acid. To this solution four grams of tartaric acid were added and, as soon as this was thoroughly dissolved, ten cc. of ammonium hydroxide (sp. gr. 0.932). To this (after filtering off slight impurities brought in with the tartaric acid) ten cc. of the above mentioned cupric solution (containing 0.0999 grams copper) were added, the whole transferred to a platinum dish having a capacity of about $200 \mathrm{cc}$, and the solution diluted to $75 \mathrm{cc}$. with distilled water. A current, generated by five or six gravity cells coupled in series, was run through the solution, the anode being a flat platinum spiral. There was a voltameter also in the circuit. The precipitation was started at four P. M., and allowed to run during the night. The currents employed most successfully generated from $0.4 \mathrm{cc}$. to $\mathrm{I} .2 \mathrm{cc}$. of electrolytic gas per minute. Immediately on interrupting the current, the liquid contents of the dish (which should smell quite strongly of ammonia) must be rapidly poured off, luke-warm distilled water poured into the dish, allowed to flow around the inside and gently emptied out. The washing with warm water should be repeated three or four times quite rapidly, and be followed by similar washings with small quantities of absolute alcohol. The dish can then be carefully dried on the edge of a warm plate, allowed to cool and weighed. Great care must be exercised during the drying to see that the dish does not get too warm, or the metal will readily oxidize, for the copper deposited from an alkaline tartrate solution does not have the lustrous sheen of that precipitated from solu- 
tions containing free acid or potassium cyanide : it has a velvety dark red appearance, but is thoroughly adherent to the dish. If the current is strong enough to generate one cc. of electrolytic gas per minute the precipitation is completed in five minutes. A decided excess of ammonia has no deleterious effect. The following examples will serve to illustrate the operation:

Experiment $1 .-1087$ gram of metallic tin was dissolyed in hydrochloric acid, oxidized, evaporated to dryness, taken up with water and sodium hydroxide, filtered, neutralized with tartaric acid, four grams of solid tartaric acid and then ten cc. of ammonium hydroxide added. Ten cc. of the copper solution (0.0999 gram copper) were added, the whole transferred to a platinum dish, diluted to $175 \mathrm{cc}$., and the current applied. The current delivered $0.4 \mathrm{cc}$. of electrolytic gas per minute, and was allowed to act for seventeen hours. The deposit of copper weighed o. I00 I gram.

Experiment 2.-0.1039 gram was treated as above. Ten cc. of copper splution were used, four grans tartaric acid and fifteen cc. of ammonium hydroxide added, and a current generating one cc. of electrolytic gas per minute acted for fifteen and one. half hours. The precipitated copper weighed 0.0997 gram.

Expcriment 3.-0.1044 gram of tin was treated as before: Four grams of tartaric acid and twenty $c c$, of ammonium hydroxide added, together with ten ec. of the copper solution. A current generating $1.2 \mathrm{cc}$. electrolytic gas per minute acted for five hours. The deposited metal weighed 0.0997 gram.

It having now been found possibie to separate copper from arsenic, from antimony, and from tin, my attention was next turned to the possibility of separating copper from the other three collectively.

COPPER FROM ARSENIC, ANTIMONY, AND TIN.

Here, gunded by the experience of Smith, Frankel, and Wallace, I decided to have the three acid oxides in their highest state of oxidation. Accordingly the solutions were made up as follows: A quantity of arsenious oxide weighing 3.3342 grams was dissolved in nitric acid (sp. gr. I.3), and the solution evaporated to dryness. The arsenic acid thus formed was taken up with water, any slight impurities filtered off, and the filtrate 
diluted to $250 \mathrm{cc}$. with distilled water. This gave a solution containing 0.1009 gram metallic arsenic in each ten cc. For the antimonic solution a portion of potassio-antimonious tartrate, $\mathrm{C}_{4} \mathrm{H}_{4}(\mathrm{SbO}) \mathrm{KO}_{6}+\frac{1}{2} \mathrm{H}_{2} \mathrm{O}$, was dissolved in water, diluted largely, and then boiled with addition of bromine water until the solution remained discolored for a considerable time by the bromine, thus indicating the complete oxidation of the antimony. The addition of a small quantity of tartaric acid prevented the slight tendency to precipitation of oxysalts. The solution was filtered and diluted to $250 \mathrm{cc}$., thus giving 0.1024 gram metallic antimony in each ten cc. The tin solution was prepared as described under the section on copper and tin, and was made of such a strength as to contain O.IO3 I gram metallic tin to every ten cc. The copper solution was made by dissolving a little more than twenty grams of copper sulphate and diluting to 500 cc. Ten cc. of this solution as determined by direct trial contained 0.1016 gram metallic copper.

The solution which proved best for the separation contained eight grams of tartaric acid, thirty-one cc. of ammonium hydroxide, and ten cc. of each of the solutions of copper, antimony, arsenic, and tin described above. Five hours proved sufficient time, and a current generating $0.8 \mathrm{cc}$. electrolytic gas per minute proved of sufficient strength to effect a thorough precipitation of the copper entirely free from any of the other three metals. The copper has the same appearance as when separated from tin, and must be washed and dried in the same way. It is, however, absolutely necessary to keep the quantity of tartaric acid and of free ammonia as high as indicated or antimony to the amount of fully one-half of that present will be precipitated. I give the following results :

Experiment 1 .- Eight grams of tartaric acid were dissolved in water, thirty cc. of ammonium hydroxide added, and the solution filtered. To this were added ten cc. of each of the solutions of arsenic, antimony, tin, and copper (o.1016 in ten cc.) previously mentioned, and the solution diluted to 175 cc. The current generated $0.8 \mathrm{cc}$. electrolytic gas per minute, and was allowed to act for five hours. The precipitated copper weighed 0.1019 gram. 
Experiment 2.-Exactly the sance quantities as in I were exposed with the same strength of current and for the same length of time. This resulted in the deposition of o.rolo grann of metallic copper instead of 0.1016 gram.

Having thus succeeded in the separation of copper, I next directed my attention to cadminm, and as antimony seemed to give the nost trouble I began with the separation of

\section{CADMIUM FROM ANTIMONY.}

The antinony solution was the one previously described. The cadnium solution was the nitrate and contained 0.09 I 6 gram of the metal in ten cc. of solution as determined by electrolytic depositiun from the cyanide solution. There is only one difficulty presented in this separation, and that is that the current must be weak, or the deposited cadnium will be too spongy to wash. Accordingly, it is necessary to allow the current to act through the night. The deposit of metal shows a tendency to form spongy masses here and there. These can be washed without loss if care be exercised in pouring the wash water on and off. The dish containing the deposit is washed with water simply-the washing with alcohol being unnecessary-and then dried on the edge of the hot plate. As actual results I give tile following:

Experiment 5 .-Five grams of tartaric acid were dissolved in hot water, fifteen cc. of ammonium hydroxide were added, and the solution filtered free from impurities introduced by the acid. Ten cc. of the antimony solution and ten cc. of the cadmium solution (0.0916 gram metallic cadmium) mentioned above were added, the whole transferred to a platinum dish, diluted to 175 cc., and the current allowed to act over night. The cadmium was washed with hot water and dried. It weighed 0.0920 gram.

Experiment 2.-The solution here was made up in the same way as in the preceding experiment. The current gave $0.3 \mathrm{cc}$. electrolytic gas per minute. It acted over night. The cadmium deposit weighed 0.0925 gram.

Experiment 3.-The solution was just the same as in the last case. The current gave $0.4 \mathrm{cc}$. electrolytic gas per minute and acted for sixteen hours. The deposit of metallic cadmium weighed 0.0925 gram. 


\section{CADMIUM FROM TIN.}

In this case the tin solution was the same as that employed in the separation of arsenic, antimony, and tin from copper, and indeed, throughout the rest of these trials the arsenic solutions (0.1009 gram metallic arsenic in ten cc.), the tin solutions (o.ro3 I gram metallic tin in ten cc.), and the antimony solutions ( 0.1024 gram of antimony in ten cc.) are the same. The separation presents no difficulties and the metal is deposited in good form if the precaution previously mentioned is observed, namely, to use a long-continued weak current. The metal should be washed with hot water only, and dried on the edge of a warm plate.

Experiment 1.-Five grams of tartaric acid were dissolved in water, fifteen cc. of ammonium hydroxide added, then ten cc. of the tin solution, and ten $\mathrm{cc}$. of the cadmium solution (0.09 5 gram). This rvas diluted to $75 \mathrm{cc}$. in the platinum dish, and a current liberating $0.1 \mathrm{cc}$. of electrolytic gas per minute allowed to act upon the mixture for eighteen and one-half hours. The cadmium deposit was washed with hot water, dried and weighed. It equaled 0.0914 gram.

Experiment 2.-The conditions and quantities were here just the same as in the last experiment save that the current delivered $0.2 \mathrm{cc}$. of electrolytic gas and was allowed to act for eighteen hours. The cadmium weighed 0.09 I 8 gram.

\section{CADMIUM FROM ARSENIC.}

The solutions employed in this case were those used previously. The amount of tartaric acid was five grams and of ammonium hydroxide fifteen $\mathrm{cc}$. This quantity proved the best for all separations where but two metals were present and was adhered to under these circumstances throughout the rest of the work. When more than two elements are present it becomes necessary to increase the amounts of tartaric acid and of ammonium hydroxide to eight grams and thirty cc. respectively. The tartaric acid was dissolved in water as before, the ammonium hydroxide added, followed by the arsenic and cadmium, the solution transferred to the platinum dish, diluted to $175 \mathrm{cc}$, and then electrolyzed. The deposit differed in no wise from that obtained in the separation of cadmium from tin. 
Exporiment 1.-Five grans of tartaric acid were dissolved in water, fifteen ce. of ammonium hydroxide were alded, followed

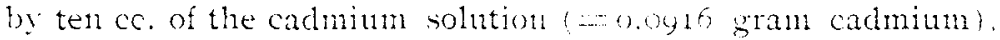
and ten ce. of the arsentc solution. The nixture was introduced into a platinum dish, diluterl to $1,5 \mathrm{cc}$. and a current that gave $0.3 \mathrm{cc}$. of electrolytic gas per minute allowed to act for a period of sixteen hours. The cadminn deposit weighed 0.09 I 3 gram.

Experiment 2.- Like quantities were taken and treated in the same manner, except that the current delivered $0.2 \mathrm{cc}$. of electrolytic gas per minute. It acted sixteen hours. The cadmium deposit weighed 0.0921 gram.

CADMICM FROM ARSHAL, ANTIMONY, ANI TIN.

The solution was now nade up by combining the arsenic, antimony, and tin with the cadnium. The tartaric acid was increased to eight grams and the ammonium lydroxide to thirty cc. The cadmium separated from the three differed in no respect from that separated from any one. It had the same appearance and washed and dried in the same way.

Experiment 1.- Eight grams of tartaric acid were dissolved in water, thirty cc. of ammonium hydroxide were added, followed by ten cc. each of arsenic, antimony, tin, and cadmium solutions. The current liberated $0.25 \mathrm{cc}$. of electrolytic gas per minute and acted for eighteen hours. The metallic cadmium weighed 0.0915 gram.

Experiment 2.-The same quantities were used as in experiment $I$. The current gave $0 .+$ cc. of electrolytic gas per minute and acted sixteen hours. The deposit of cadmium weighed 0.0920 gram.

Experiment 3.--Same quantities were used. The current gave $0.3 \mathrm{cc}$. of electrolytic gas per minute and precipitated 0.0918 gram cadmium.

Copper and cadmium having yielded thus easily to the current in the presence of arsenic, antimony, and tin in ammonium tartrate solutions, my attention was next turned to bismuth.

\section{BISHUTH FROM ARSENIC.}

The solution was made by dissolving 5.8 grams of bismuth nitrate in water acidulated with enough nitric acid to prevent the formation of basic salts. The solution was diluted to $400 \mathrm{cc}$. 
and ten cc. taken for the determination of the bismuth. The metal was precipitated from the alkaline tartrate solution and weighed 0.0518 gram. The practice had now become uniform of adding five grams of tartaric acid and fifteen cc. of ammonium hydroxide when two metals were present, and eight grams of acid and thirty cc. of ammonium hydroxide when four metals were in the same solution. The solution was made up as in all preceding cases and the process differed in no way until the washing began. Bismuth does not form so compactly on the dish as cadmium does or even as copper from the alkaline tartrate solution. Accordingly great care was necessary in the washing. In drying, too, it seemed to oxidize with very little heating. Therefore, when the deposition was complete the anode was raised, the liquid gently but quickly decanted from the deposited bismuth, and the wash water gently poured on and off. This latter was repeated three or four times, and was followed by three or four washings with absolute alcohol. The dish was placed on a very moderately heated plate and the evaporation of the alcohol facilitated by gentle blowing. It is best to use a long-continued weak current for bismuth or the deposit will be spongy and loose, rendering washing difficult.

Experiment 1 . - The solution contained five grams of tartaric acid, fifteen cc. of ammonium hydroxide, 0.1009 gram metallic arsenic, and $0.05 \mathrm{I} 8 \mathrm{gram}$ of bismuth. It was diluted to $175 \mathrm{cc}$. The current acted sixteen hours and gave $0.3 \mathrm{cc}$. of electrolytic gas per minute. The precipitated bismuth weighed 0.0514 gram.

\section{BISMUTH FROM ANTIMONY.}

Here the procedure was exactly similar to that described under the separation of bismuth from arsenic. The precipitated metal resembled that obtained in the preceding experiment.

Experiment 5 . - The solution contained five grams of tartaric acid, fifteen cc. of ammonium hydroxide, 0.1024 gram of antimony, and 0.0518 gram of bismuth. It was diluted to $175 \mathrm{cc}$. The current gave $0.22 \mathrm{cc}$. of electrolytic gas per minute. It acted sixteen and one-half hours. The deposit of metallic bismuth weighed 0.0513 gram. 
BISALTII FROA TIX.

The method of procedure was just the same here as in the separation of antimony or of arsenic from bismuth. The piecipitated bismuth was treated as heretofore and had the same appearance.

Experiment.-The solution contained five grams of tartaric acid, fifteen cc. of ammonium hydroxide, 0.103 I gram of metallic tin and $0.05 \mathrm{I} 8 \mathrm{gram}$ of metallic bismuth. It was diluted with distilled water to $175 \mathrm{cc}$. The acting current gave $0.2 \mathrm{cc}$. of electrolytic gas per minute; time, sixteen and one-half hours. The bismuth deposit weinhed 0.0514 gram.

BISMTH FROM ARSHNC, ANTMONY, AND TIN.

The procedure was anain just as before. The bismuth precipitated readily and in as clean a form as when separated from each of the metals singly.

Experiment.-The solution contained 0.05 I 8 gran of bismuth, O. I009 grani of arsenic, $0.102+$ gram of antimony, 0. IO3I gram of tin, eight granss of tartaric acid, thirty cc. of ammonium hydroxide, and was diluted to $175 \mathrm{cc}$. The current gave $0.2 \mathrm{cc}$. of electrolytic gas per minute and was allowed to act for sixteen and one-half hours. The bismuth, after washing and drying, weighed 0.0513 gram.

The method adopted by me having proved successful in the separation of copper, cadmium, and bismuth from the metals forming acid oxides, I next applied it to the study of mercury in its bivalent form. A bout seven grams of mercuric chloride were dissolved in distilled water and diluted to $500 \mathrm{cc}$. Ten cc. of this solution proved to contain 0.0933 gram of metallic mercury. I first undertook the separation of

MERCURY FROM TIX.

There was a doubt in my mind whether the mercuric compound could be made up in alkaline tartrate solution when there was so much free ammonia present: I found, however, that if the mercuric chloride solution be added to the tartaric acid solution before the addition of the ammonia there is little likelihood of trouble, though even then the double compound sometimes forms, especially if the solutions be not dilute. But 
if care be exercised the mercuric salt may be added last. If the solution is well diluted and the mercuric salt added with constant stirring all remains in solution very nicely. The mercury and tin were then combined with the tartaric acid and ammonia, the solution diluted, and the current passed. The precipitation is quite rapid even with a fairly weak current, and the metal separates as a lustrous coating having a very slight tendency to drops. The mercury is washed with very warm water three or four times and then dried by keeping the dish in the warm hand and blowing gently into it to facilitate the evaporation. Any attempt to dry it on the plate is attended with very considerable risk of vaporizing a portion of the mercury.

Experiment.-Ten cc. of the mercuric chloride solution (=0.0933 gram metallic mercury, ten cc. of tin solution, five grams of tartaric acid, and fifteen $c c$. of ammonium hydroxide were united and diluted to $75 \mathrm{cc}$. The current gave $0.2 \mathrm{cc}$. of electrolytic gas per minute and was continued for six hours. The mercury deposit weighed 0.0930 gram.

\section{MERCURY FROM ARSENIC.}

The solution contained 0.0933 gram of mercury, 0.1009 gram of arsenic, five grams of tartaric acid and fifteen cc. of ammonium hydroxide. It was diluted to $175 \mathrm{cc}$. The current gave $0.33 \mathrm{cc}$. of electrolytic gas per minute, acted for five hours, and deposited 0.0928 gram of metallic mercury.

MERCURY FROM ANTIMONY.

Experiment.-The solution contained 0.1024 gram of antimony in addition to the nercury, also five grams of tartaric acid and fifteen cc. of ammonium hydroxide. It was diluted to I 75 cc. with water. The current gave $0.5 \mathrm{cc}$. of electrolytic gas per minute. It acted for six hours and precipitated $0.093^{2}$ gram of metallic mercury.

MERCURY FROM ARSENIC, ANTIMONY, AND TIN.

The solution was made up in the same manner as in the three preceding separations, save for the increase of tartaric acid and of ammonium hydroxide. There was, however, a difference in the nature of the deposited mercury. A part of it gathered as in the other cases in a lustrous coating on the sides of the dish, 
but in addition to this there was quite a considerable amount of mercury in the form of drops so small as to be almost pulverulent. This rendered washing exceedingly difficult. The fluid contents of the dish, after the anode has been raised, are carefully decanted from the powder boiling water adied, allowed to flow around the dish, and again very carefully decanted. This was repeated six or seven times, never draining off the last drops to avoid loss of the mercury. If this care is taken there is no difficulty about good results, but the slightest haste results in the loss of mercury. Naturally when that much water remains on the mercury the evaporation from the heat of the hand is a most tedious, but the only safe. process.

Experiment 1. The solution contained 0.0933 gram of mercury, 0.1009 gram of arsenic, 0.1024 gram of antimony, $0.103 \mathrm{r}$ gram of tin, eight grams of tartaric acid. thirty $c c$. of ammonium hydroxide, and was diluted to $175 \mathrm{cc}$. The current gave $0.5 \mathrm{cc}$. of mixed gases per minute. It acted for sixteen hours and precipitated 0.0935 gram of mercury.

Experiment 2.-The conditions were the same as in the first experiment. The current gave $0.4 \mathrm{cc}$. of electrolytic gas per minute and precipitated 0.0933 gram of metallic mercury.

I made no attempt to separate lead from arsenic, antimony or tin.

In conclusion, I would acknowledge my indebtedness to Prof. Edgar F. Smith, at whose suggestion and under whose supervision the above studies were brought to completion.

UNIVERSITY OF PENNSYLVANia,

IULY $Y, 189.3$.

\section{THE ACTION OF GASES UPON METALLIC MOLYBDENUM AND TUNGSTEN.}

BY EDGAK F, SMITH AII VICKFRS OREKHOITZER.

Received fuly 12, 1803 .

A VING prepared these two metals with care and believing
then to possess a high degree of purity, we conceived that it
might be of interest to observe their behavior when exposed, at more
or less elevated temperatures, to the influence of different gases.
We first studied their conduct in an atmosphere of carbon mon- 